\title{
Micro-hardness of surface layer of irradiated polypropylene
}

\author{
David Manas $^{a}$, Martin Ovsik, Miroslav Manas, Michal Stanek, Lenka Gajzlerova, Martin Mizera, Libor \\ Gabko and Lenka Hylova
}

Tomas Bata University in Zlin, TGM 5555, 76001 Zlin, Czech Republic

\begin{abstract}
Using high doses of beta radiation for polypropylene (PP) and its influence on the changes of micromechanical properties of surface layer has not been studied in detail so far. The specimens of PP were made by injection moulding technology and irradiated by high doses of beta radiation $(0,33$, and $66 \mathrm{kGy})$. The changes in the microstructure and micromechanical properties of surface layer were evaluated using WAXS and instrumented microhardness test. The results of the measurements showed considerable increase in micromechanical properties (indentation hardness, indentation elastic modulus) when high doses of beta radiation are used.
\end{abstract} Keywords: polypropylene (PP), microhardness, micromechanical properties, surface layer, $\beta$-irradiation, WAXS.

\section{Introduction}

Instrumented indentation has been in use already for several decades, as a technique to probe mechanical properties of small volumes of materials [1] and [2]. In metals, in which the technique was first applied, the technique allows to probe several macroscopic properties, like hardness, Young modulus, yield strength, strain hardening exponent, among others [1-6].

Irradiation of a polymer by different radiations leads to several physicochemical changes, a few of which include scissioning and or crosslinking, carbonization, conjugation, oxidation, creation of defects, generation of low molecular weight fragments and evolution of gases. These changes induce considerable modifications in mechanical, electrical, thermal and optical properties of polymers and are qualitatively or quantitatively based on properties of radiation and the polymer.

Isotactic polypropylene (iPP) is a commodity polymer with the semi-crystalline structure which is very complex and depends strongly on thermal history and processing conditions. Isotactic polypropylene can crystallize in to 3 phases: $\alpha$-phase is the most stable and the most known. The crystals are monoclinic. Beta phase is metastable and the crystals are hexagon 1 -phase is mainly found in block PP copolymers and can be generated by addition of specific nucleating agents. This phase was discovered by Padden and Keith in 1953 and can be improved by crystallization between 130 and $132{ }^{\circ} \mathrm{C}$ or by orientation with high shear or through addition of specific nucleating agents. Presence of $\square$-phase in PP homopolymer generally increases ductility in the finished parts. Maximum effect is observed at $65 \%$ of beta-phase. Gamma phase - this phase is also metastable with triclinic crystals. This form is not

${ }^{\text {a }}$ Corresponding author: dmanas@ft.utb.cz 
very familiar but appears mainly in low molecular weight polypropylene by crystallization at very high pressure and very low cooling rate [1-7].

\section{Experimental}

\subsection{Material and methods}

For this experiment polypropylene (homopolymer) Moplen HP3175 LyondellBasell company was used. Polypropylene (PP) Moplen HP3175 is suitable for injection moulding applications and can also be used in technical compounds as a base resin. It has a high melt flow rate and it is supplied in pelletized form with density $0.9 \mathrm{~g} \mathrm{~cm}^{-3}$, with high crystallinity and high stiffness. Melt flow index was measured $\left(230{ }^{\circ} \mathrm{C} / 2.16 \mathrm{~kg}\right) 40 \mathrm{~g} / 10 \mathrm{~min}$. The material does not contain a special cross-linking agent TAIC - triallylisocyanurate, which should enable subsequent cross-linking by ionizing $\beta$-radiation. Irradiation was carried out in the company BGS Beta Gamma Service GmbH \& Co, KG, Germany with the electron rays, electron energy $10 \mathrm{MeV}$, doses minimum of 0,33 and $66 \mathrm{kGy}$ on air the ambient temperature.

The samples were made using the injection molding technology on the injection moulding machine Arburg Allrounder $420 \mathrm{C}$. Processing temperature $190-230{ }^{\circ} \mathrm{C}$, mold temperature $40{ }^{\circ} \mathrm{C}$, injection pressure $80 \mathrm{MPa}$, injection rate $50 \mathrm{~mm} / \mathrm{s}$. [7-9]

\subsection{Micro-indentation test}

Micro-indentation test was done using a Micro Combi Tester, CSM Instruments (Switzerland) according to the CSN EN ISO 14577. Load and unload speed was $1 \mathrm{~N} / \mathrm{min}$. After a holding time of $90 \mathrm{~s}$ at maximum load $0.5 \mathrm{~N}$ the specimens were unloaded. The specimens were glued on metallic sample holders. Poisson's ratio $(v)$ of the polymer was 0.3 . The indentation hardness $\left(\mathrm{H}_{\mathrm{IT}}\right)$ was calculated as maximum load $\left(\mathrm{F}_{\max }\right)$ to the projected area of the hardness impression $\left(\mathrm{A}_{\mathrm{p}}\right.$ according to: [7-10].

$$
\boldsymbol{H}_{I T}=\frac{\boldsymbol{F}_{\max }}{\boldsymbol{A}_{P}}
$$

\subsection{Results and discussion}

The development of micromechanical properties of irradiated polypropylene was characterized by the instrumented test of microhardness $\left(\mathrm{H}_{\mathrm{IT}}\right)$, as can be seen in Fig. 1. The lowest values (94 MPa) of indentation hardness were found on non-irradiated polypropylene, while the highest value of indentation hardness $(101 \mathrm{MPa})$ was measured at $66 \mathrm{kGy}$ radiation dose. The values $(100 \mathrm{MPa})$ of indentation hardness were found on polypropylene irradiated with radiation dose of $33 \mathrm{kGy}$ radiation dose. The increase of indentation hardness at $66 \mathrm{kGy}$ radiation dose was by $7 \%$ compared to the non-irradiated polypropylene.

Similar development was recorded for microstiffness of specimens represented by the elastic modulus of indentation $\left(\mathrm{E}_{\mathrm{IT}}\right)$ illustrated in Fig. 2. The results of measurements show clearly that the lowest values of microstiffness were measured on the polypropylene $(1.92 \mathrm{GPa})$ irradiated with radiation dose of $33 \mathrm{kGy}$, while the highest values were reached in polypropylene irradiated by $66 \mathrm{kGy}$ dose $(2.03$ $\mathrm{GPa})$. Lower value (1.93 $\mathrm{MPa})$ of microstiffness, were found on non-irradiated polypropylene. A decrease of microstiffness $(5 \%)$ was recorded at the radiation dose of $66 \mathrm{kGy}$ compared to the non-irradiated polypropylene. 


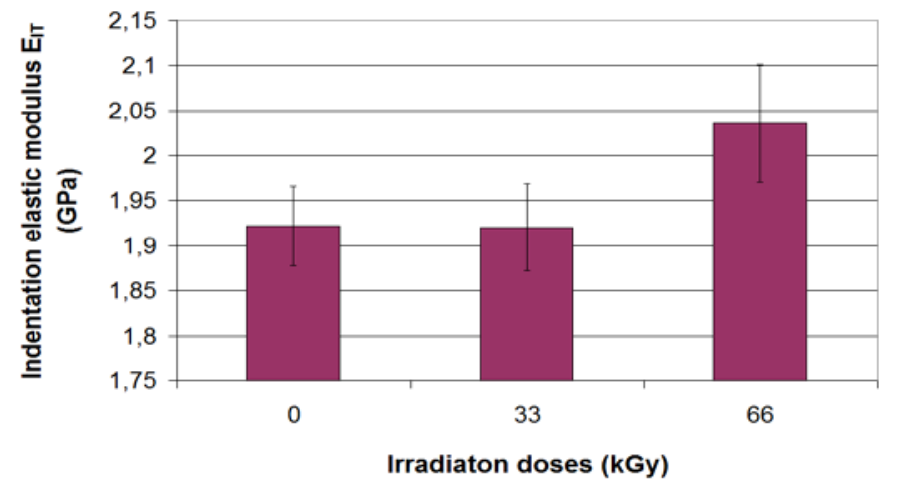

Figure 1. Indentation hardness vs. irradiation doses.

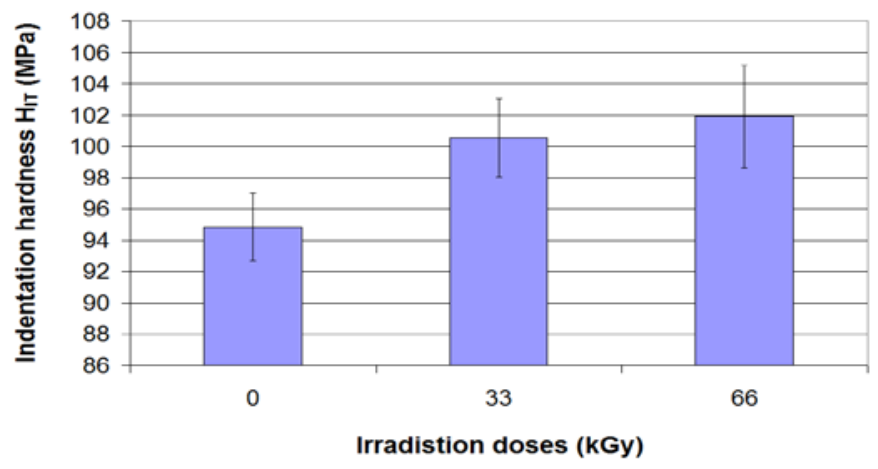

Figure 2. Indentation elastic modulus EIT.

Other important material parameters obtained during the micro-hardness test were elastic and plastic deformation work. The mechanical work $\mathrm{W}_{\text {total }}$ induced by the indentation is only partly consumed as plastic deformation work $\mathrm{W}_{\text {plast }}$. During the removal of the test force the remaining part is set free as work of the elastic reverse deformation $\mathrm{W}_{\text {elast }}$.

The highest values of plastic deformation work were obtained for non-irradiated polypropylene. The highest values of elastic deformation work were obtained for polypropylene irradiated with radiation dose of $66 \mathrm{kGy}$. The lowest values of $\mathrm{W}_{\mathrm{el}}$ were obtained for polypropylene irradiated with dose of 33 $\mathrm{kGy}$. The highest values of plastic deformation work $\left(\mathrm{W}_{\mathrm{pl}}\right)$ were obtained for polypropylene irradiated with radiation dose of $66 \mathrm{kGy}$. The lowest values of $\mathrm{W}_{\mathrm{pl}}$ were obtained for polypropylene irradiated with dose of $0 \mathrm{kGy}$. Radiation of specimens caused lower values of plastic deformation work which is in Fig. 4.

Very important values were found for indentation creep. For materials which creep as polymers, a basic calculation of that creep can be measure during a pause at the maximum force. The creep is the relative change of the indentation depth when the test force is kept constant measured by instrumented test of microhardness showed (Fig. 3) that the lowest creep values were measured on non-irradiated polypropylene $(10.5 \%$ ), while the highest creep value was found in polypropylene irradiated by $66 \mathrm{kGy}$ dose $(11.3 \%)$. The creep increase by $9 \%$ as a result of radiation, which represents a considerable decrease of surface testing layer's mechanical properties 


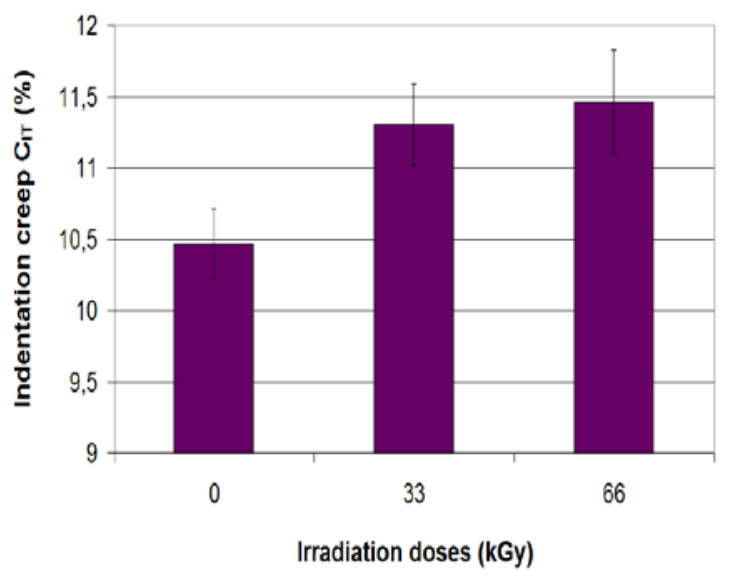

Figure 3. Indentation creep CIT.

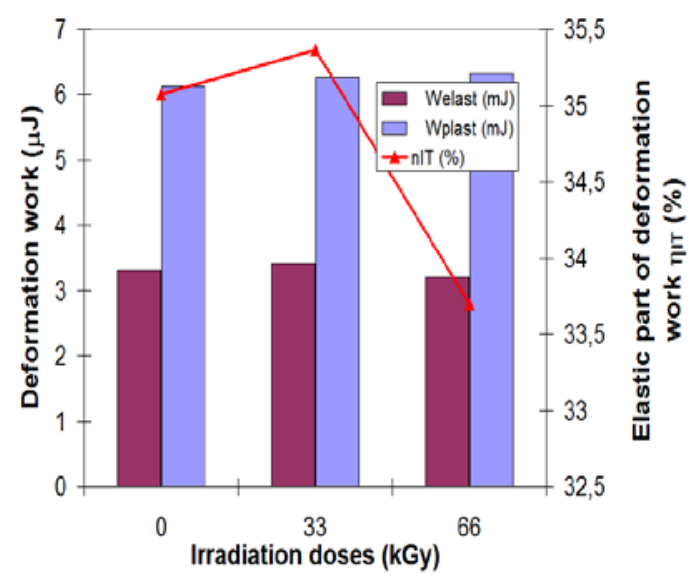

Figure 4. Deformation work vs. irradiation dose.

Higher radiation dose does not influence significantly the micro-hardness value. An indentation hardness increase of the surface layer is caused by irradiation cross-linking of the tested specimen. A closer look at the micro-hardness results reveals that when the highest radiation doses are used, micro-hardness decreases which can be caused by radiation induced degradation of the material.

\section{Conclusions}

The experimental study deals with the effect of modification of the surface layer by irradiation cross-linking on the properties of the surface layer of polypropylene. Polypropylene was modified by beta irradiation at doses of 0,33 and $66 \mathrm{kGy}$. The changes of micromechanical properties were found at the radiation dose of $66 \mathrm{kGy}$ for indentation hardness (which increased by $7 \%$ ) compared to the non-irradiated polypropylene. Improvement of mechanical properties in micro and macro scale of radiated polypropylene has a great significance also for industry. The modified polypropylene shifts to the group of materials which have considerably better properties. Its micromechanical properties make polypropylene ideal for a wide application in the areas where higher resistance to wear, scratch are required. 


\section{Acknowledgments}

This work was supported by the Ministry of Education, Youth and Sports of the Czech Republic within the National Sustainability Programme project No. LO1303 (MSMT-7778/2014) and also by the European Regional Development Fund under the project CEBIA-Tech No. CZ.1.05/2.1.00/03.0089 and the internal grant of TBU in Zlin No. IGA/FT/2016/010 funded from the resources of specific university research and by the Ministry of Education, Youth and Sports of the Czech Republic.

\section{References}

1. M. Ovsik, D. Manas, M. Manas, M. Stanek, M. Hribova, K. Kocman, D. Samek: Irradiated Polypropylene Studied by Microhardness and WAXS, Chemicke listy, 106 (2012), 507-510.

2. J. Gheysari et al., The effect of high-energy electron beam on mechanical and thermal properties of LDPE and HDPE, Eur. Polym. J. 37 (2001) 295-302.

3. Makuuchi, S. Cheng, Radiation processing of polymer materials and its industrial applications, Wiley, Hoboken, 2011.

4. G. Drobny, Ionizing radiation and polymers: principles, technology and applications. Elsevier, Oxford, 2013.

5. L. Chvatalova, J. Navratilova, R. Cermak, M. Raab, M. Obadal. Joint effects of molecular structure and processing history on specific nucleation of isotactic polypropylene Macromolecules, 42 (2009), pp. 7413-7417.

6. G. Zamfirova, V. Gaydarov, T. Zaharescu, L. G. Silva: Microindentation study of Electron Beam Irradiated Polyamide Samples, Chemicke Listy, 104 (2010), 283-286.

7. D. Manas, M. Hribova, M. Manas, M. Ovsik, Stanek: Effect of Beta Irradiation on Morphology and Microhardness of Polypropylene Thin Layers, Thin Solid Films 530, (2013), 49-52.

8. Uzuna, U. Kölemena, S. Çelebi, N. Güçlü, Modulus and hardness evaluation of polycrystalline superconductors by dynamic microindentation technique, Journal of the European Ceramic Society. 25 (2005) 969-977.

9. W. C. Oliver, G. M. Pharr. An improved technique for determining hardness and elastic modulus using load and displacement sensing indentation, J Mater Res 7. (6) (1992) pp. 1564-1583.

10. Ragan, P. Baron, J. Dobránsky. Sucking machinery of transport for dosing granulations of plastics at injection moulding. Advanced Materials Research (2012), 383-390, 2813-2818. 